Sharif University of Technology
Scientia Iranica
Transactions E: Industrial Engineering
http://scientiairanica.sharif.edu
IRA I ENTIA

\title{
A system dynamics model for evaluating the firms' capabilities in maintenance outsourcing and analyzing the profitability of outsourcing
}

\author{
H. Kaveh Pishghadam and H. Esmaeeli* \\ Department of Industrial Engineering, North Tehran Branch, Islamic Azad University, Tehran, P.O. Box 1651153311, Iran.
}

Received 25 December 2019; received in revised form 28 October 2020; accepted 1 March 2021

\section{KEYWORDS \\ Maintenance; \\ Outsourcing; \\ Efficacy; \\ Profitability; \\ Equipment \\ effectiveness.}

\begin{abstract}
Outsourcing is recognized as a tool to gain strategic advantages. Maintenance outsourcing is a common practice in many industries, including chemical, petroleum, petrochemical, and medical equipment manufacturing. Nevertheless, outsourcing is associated with many risks. This study designed a model based on the system dynamics to identify variables that affect the effectiveness of equipment, efficacy, and profitability. Moreover, the extent of the effects of these variables was examined and their relationships to decide on maintenance outsourcing in gas refineries were assessed. First, the influential variables were identified by reviewing the literature and considering experts' opinions. Next, a system dynamics model was designed, and the optimal values of the variables were investigated by creating five different scenarios. The results showed how the investigated variables affected our objectives and how we could achieve them by keeping the values of these variables close to those determined in the selected scenarios. If the variable of equipment effectiveness was preferred by the managers, Scenario 3 would be selected, as the equipment effectiveness reached its maximum level in this scenario. On the other hand, if the efficacy and profitability variables were preferred, Scenario 4 would be selected in which efficacy and profitability were at maximum levels.
\end{abstract}

(C) 2023 Sharif University of Technology. All rights reserved.

\section{Introduction}

Automated systems have gained important competitive advantages in industrial plants. Considering the need for rapid turnarounds and extensive supply of products, manual conduct comes at the expense of companies $[1,2]$. Further, automation enables real-time control, processing, tracking, and production manage-

*. Corresponding author. Tel.: +98 21 r7318799

E-mail addresses: h.kavehpishghadam@iau-tnb.ac.ir (H.

KavehPishghadam); h_esmaeili@iau-tnb.ac.ir (H. Esmaeeli)

doi: $10.24200 /$ sci.2021.55108.4080 ment while reducing the labor costs and increasing the efficiency and accuracy. When a company invests in automated systems, it should be able to maintain and protect its technology and equipment against failure and early depreciation [3,4]. Therefore, many factory managers are faced with difficult decisions as to whether they should outsource the equipment maintenance or employ an internal team for this purpose $[3,4]$.

Conventionally, it is rationalized that a company should only outsource its non-fundamental activities. However, this approach does not provide any guidance about selecting such activities. Also, the debate about fundamental and non-fundamental activities is highly controversial in many organizations adopting 
this approach $[1,5]$. On the other hand, determining the impact of failure is one of the most important considerations during the process of decision-making about maintenance outsourcing [6,7]. It is known that failure directly affects efficacy and profitability. Therefore, having in-house personnel to deal with problems in the event of failure is a significant advantage. Moreover, having a maintenance team with proper skills can significantly reduce the repair time $[2,8]$. Overall, when deciding on whether to hire a maintenance team or outsource it to a contractor, it is important to determine whether the existing team has adequate skills to handle the problem.

As Pascual et al. [8] stated, failure affects the efficacy and profitability of an organization. Therefore, to increase efficacy and profitability, failures should be avoided as much as possible, or the maintenance time should be minimized in the event of a failure. The present study aimed to investigate the outsourcing of maintenance activities in a gas refinery plant and to analyze the post-outsourcing efficacy and profitability using a system dynamics model. For this purpose, by identifying and determining the influential variables and examining their relationships, a system dynamics model including the three variables of equipment effectiveness, efficacy, and profitability was designed to determine their effects on one another and to propose more suitable plans for achieving the organizational goals based on these relationships.

The remainder of this paper is organized as follows. Section 2 reviews the literature review and recent advances in this area. Section 3 deals with the proposed methodology. Section 4 proposes the case study and an extensive analysis. Finally, Section 5 presents practical implications, findings, and conclusions.

\section{Literature review}

Today, Maintenance, Repair, and Overhaul (MRO) is the cornerstone of the growth of any organization. The role of MRO is critical in organizations such as gas refineries where the production process is continuous and the products are essential to the community [9]. The MRO may be defined as "all the measures taken to maintain or restore an item or status in order to perform the function required" [10]. They include a combination of all technical, administrative, management, and monitoring measures. This section reviews the literature on maintenance and outsourcing [11].

According to our literature review, previous studies have used different outsourcing approaches. For example, the repair and maintenance cost model, presented by Stenström et al. [12], aimed at evaluating performance and deciding on the pricing of maintenance services, contract negotiations, outsourcing, and life cycle cost management. Moreover, Krstić and
Marenjak [13] developed and validated a new model for estimating the average annual costs of maintenance and exploitation of buildings at the University of Osijek (Osijek, Croatia). Moreover, Lundgren et al. [14] reported that Value-Driven Maintenance (VDM) was a maintenance management model, which aimed to add value and profit to the company. Values influencing the maintenance profit, resource allocation, cost control, and Health, Safety, and Environment (HSE) were also described [15]. The present value of VDM is defined as the index of profit, calculated by the difference between cash outflow and inflow [16].

There are many examples of repair and maintenance in previous studies on waste reduction. In this regard, Diallo et al. [17] introduced procedures for reducing the maintenance waste. In terms of Total Quality Maintenance (TQM), Fraser et al. [18] found that TQM represented a model functioning based on the Plan-Do-Check-Act (PDCA) method used to improve any technical or management system. Regarding maintenance investments, different models including financial investment maintenance, technical impacts of operation-level investment, lower failure rates, shorter stoppage, and higher quality have been introduced in various studies, including the one conducted by AlNajjar [19].

To increase the effectiveness of dynamic decisionmaking for manufacturing and maintenance, Sharma et al. [20] identified, measured, and controlled losses during production, tracked changes in maintenance, and evaluated their impact on the increased production time. Many studies have evaluated the ReliabilityCentered Maintenance ( $\mathrm{RCM}$ ), which is a planning approach for maintenance activities with focus on the functions of a system [20,21]; this strategy was first introduced by Ross et al. [22]. Moreover, Afzali et al. [23] presented a new model of RCM prioritization for the distribution feeders. Rafiei et al. [24] suggested a new approach to the utilization of RCM in a protection remote-control system based on smart grids.

Risk-based maintenance is another strategy that was used by Cheng et al. [25] in their proposed Riskbased Evaluation Model for Bridge life-cycle Maintenance Strategy (REMBMS). Özkan and Bulkan [26] employed this strategy for repair and maintenance planning in hydroelectric power plants, while Nielsen et al. [27] applied it in repair and maintenance planning for wind turbine blades. Regarding simulation and maintenance, the simulation-based optimization algorithm was used in many studies, including studies by Irawan et al. [28], Wakiru et al. [29], Horvath et al. [30], Packianather et al. [31], and Ganji et al. [32].

Moreover, Qin et al. [33] proposed a two-step optimization approach to aircraft hangar maintenance planning and staffing problems under outsourcing. In another study, Chen et al. [34] used the distance tree 
and Mahala Nobis decision tree to analyze the unusual patterns of behavior in the maintenance outsourcing process. Moreover, a number of studies investigated repair and maintenance outsourcing, including a study by Mokhtari and Asadkhani [35], which focused on maintenance outsourcing strategies in the software sector. In addition, Tai [36] used this method in their study for continuously degrading systems, while Bağan and Gerede [37] applied the nominal group technique to explore the safety hazards of aircraft maintenance outsourcing.

In the supply chain section, Salmasnia et al. [7] considered a supply chain that included a manufacturer and an external contractor, where the former wishes to outsource the preventive maintenance activities provided by the contractor. In this regard, Nabavi et al. [38] outsourced the repair and maintenance of refrigeration equipment. Moreover, Sosnowska et al. [39] evaluated the concept of global outsourcing as well as the process of aircraft outsourcing and the related risks. Parida and Kumar [40] focused on the transfer of knowledge about software maintenance outsourcing based on the key roles of software knowledge and guided learning tasks. Moreover, Ou et al. [41] examined outsourcing and sourcing of organizational activities and evaluated the role of outsourcing mechanisms.

So far, many studies have been published on different areas of repair and maintenance; however, limited research has been conducted in applied areas using the system dynamics models. The present study extensively evaluated maintenance resourcing. Until now, simultaneous examination of profitability, efficacy, and equipment effectiveness in the system dynamics has not been carried out, and there is limited information in this area. Therefore, the use of this model in gas refineries can be a unique strength of the present study. To cover maintenance outsourcing and analyze its profitability, the current study aimed to design a system dynamics model based on the variables presented in Table 1 to evaluate their effects on profitability, efficacy, and equipment effectiveness and to consider the model implementation in gas refineries. In the first step, effective maintenance outsourcing indicators, identified in previous studies, were evaluated, and their impacts on the profitability, efficacy, and equipment effectiveness were examined. Based on the obtained results, the system dynamics variables (profitability, efficacy, and equipment effectiveness) were defined, and different strategies and scenarios were designed.

\section{Methodology}

The system dynamics is a combination of theory, methodology, and philosophy to explain the system behavior across a wide range of disciplines such as business management, politics, economics, engineering, environmental changes, and pharmacy [38]. The system dynamics methodology provides a framework to analyze how actions and reactions create and affect one another and to explain the mechanisms and causes of elements and system changes. Moreover, it helps us understand how the system works and also predicts how situations may develop over time [39].

The main idea of system dynamics involves feedback loops that examine the interactions between different parts [34]. These loops show how changes in one part of the system may affect others including the overall pattern of development [35]. Oil and gas industries in Iran are among the key components of economy, which continuously contribute to prosperity. To gain a competitive advantage in globalization, reputable manufacturing plants seek high production efficiency and substantial cost reduction [42]. It should be noted that production performance is strongly influenced by the efficacy of repair and maintenance practices [40], since production in oil and gas industries is achieved through equipment and machinery, purchased and installed with heavy capital investments.

Major maintenance activities, such as Turn Around Maintenance (TAM), are key aids in the overall reliability and efficiency of oil and gas refinery plants. The international competition challenges have imposed significant pressure on repair and maintenance systems. On the other hand, repair and maintenance is a key element in the production processes of oil and gas industries. Generally, maintenance management aims to select the most appropriate maintenance strategy for the equipment to attain an acceptable level of safety and to achieve high reliability and availability of assets, without any unnecessary investment.

The present study aimed at investigating the impact of maintenance outsourcing on the efficiency, profitability, and effectiveness of equipment in a gas refinery plant based on a system dynamics model. The implementation steps, which are shown in Figure 1, will be explained as a case study in the following section.

\section{Case study}

Today, MRO of industrial complexes is one of the most important parts of production management in industries. Overall, maintaining physical assets, besides reducing the maintenance costs through proper operation and implementation of production methods, can reduce the production costs; this can be a type of competitive advantage for factories. In Iran, oil and gas industries are of great significance to the country's economy. The Ministry of Petroleum has always faced the challenges of optimizing maintenance, repairing systems, and reducing the overhead costs of the industry, considering the fluctuations in the prices 
Table 1. Key variables influencing maintenance outsourcing.

\begin{tabular}{|c|c|c|c|c|}
\hline Item & Index & $\begin{array}{c}\text { Auxiliary } \\
\text { variable }\end{array}$ & $\begin{array}{c}\text { State } \\
\text { variable }\end{array}$ & $\begin{array}{c}\text { Variable } \\
\text { rate }\end{array}$ \\
\hline 1 & The initial input price of the plant & $*$ & & \\
\hline 2 & Maintenance personnel cost & $*$ & & \\
\hline 3 & Equipment and machinery price & $*$ & & \\
\hline 4 & Education costs & $*$ & & \\
\hline 5 & HSE costs & $*$ & & \\
\hline 6 & Sales and customer satisfaction rate & & & $*$ \\
\hline 7 & High-quality production rate & & & * \\
\hline 8 & Operational and executive risks & $*$ & & \\
\hline 9 & Production cost of defective or poor quality products & $*$ & & \\
\hline 10 & Efficacy percentage of supply chain management & $*$ & & \\
\hline 11 & Efficacy percentage of business management and sales & $*$ & & \\
\hline 12 & Releasing resources for other goals of the organization & $*$ & & \\
\hline 13 & Outsourcing costs & $*$ & & \\
\hline 14 & Cost of spare parts and consumables & $*$ & & \\
\hline 15 & Stock price & $*$ & & \\
\hline 16 & Equipment and machinery price & $*$ & & \\
\hline 17 & Average cost & $*$ & & \\
\hline 18 & Equipment effectiveness rate & & $*$ & \\
\hline 19 & Equipment life and failure & $*$ & & \\
\hline 20 & Cost of emergency repairs and stoppage & $*$ & & \\
\hline 21 & Equipment efficacy rate & & & $*$ \\
\hline 22 & Outsourcing effectiveness rate & & & $*$ \\
\hline 23 & Average time to repair & & & $*$ \\
\hline 24 & Overhaul and recurrent maintenance costs & $*$ & & \\
\hline 25 & Technology upgrading and updating costs & $*$ & & \\
\hline 26 & Process problems costs & $*$ & & \\
\hline 27 & Defective products costs & $*$ & & \\
\hline 28 & Lost production cost due to emergency stoppage & $*$ & & \\
\hline 29 & Stoppage costs during overhaul and recurrent maintenance & $*$ & & \\
\hline 30 & Outsourcing volume & $*$ & & \\
\hline 31 & Profitability & & $*$ & \\
\hline 32 & Efficacy & & $*$ & \\
\hline 33 & Efficacy percentage of optimal management of physical assets & $*$ & & \\
\hline 34 & Equipment availability rate & & & $*$ \\
\hline
\end{tabular}

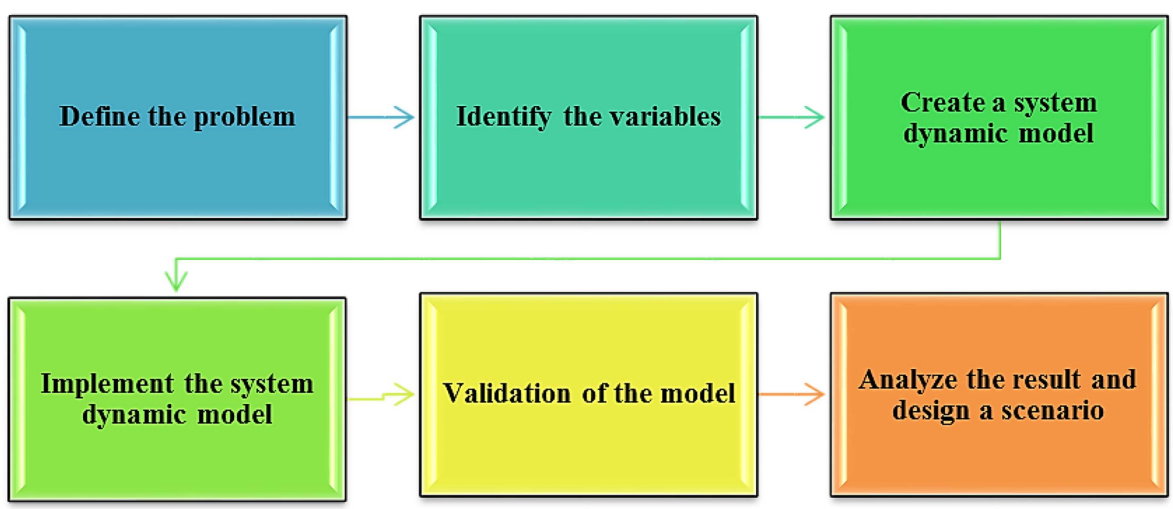

Figure 1. The study flowchart. 
of petroleum products. One of the most important solutions to reducing the cost and government ownership in this industry is to outsource the MRO of oil, gas, and petrochemical complexes.

In the history of oil industry in Iran, MRO has been discussed by the officials and authorities of the Ministry of Petroleum. Over time, the private sector has been assigned the maintenance and repair responsibilities. According to outsourcing and Operation and Maintenance (O\&M) contracts, production complexes, including refineries and petrochemical complexes, were handed over to the private sector. Overall, outsourcing in Iran requires an organizational culture, as well as reforms in some current laws and regulations. However, what is important in production on a global scale is the use of novel methods and techniques in this industry to reduce production costs and compete with other countries.

In the present study, we aimed to evaluate the new concept of outsourcing the O\&M of oil, gas, and petrochemical complexes to the private sector to reduce the cost of production by the government and to raise production. We analyzed the 9th Refinery of the South Pars Gas Complex (Persian Gulf, Iran) in terms of cost. The required information was provided by Petro Sanat Co. as the operator of the mentioned refinery during 2017-2018. We also used the opinions of experts and managers of this company, as the first company operating in the sector of refineries. Using the system dynamics, we investigated the repair and maintenance outsourcing of the gas refinery and evaluated its impact on the equipment profitability, efficiency, and effectiveness. As mentioned earlier, there are very few studies with high levels of pragmatism and practicality on the outsourcing of maintenance and repair in gas refineries. However, this study attempted to reduce the gap between science and practice. Considering the profitability, productivity, and effectiveness of equipment in the real world and the high cost of equipment, it is important to analyze them together via system dynamics. To this end, the following steps were performed:

- Step 1. Background and problem defining: The dynamic, uncertain, and complex environment of trading seems to define what is important for the commercial success of oil and gas trades. Asset operations and maintenance processes in such environments have received increased attention in recent years. Considering the current pace of development in engineering and management, asset management and its maintenance process, particularly in highrisk and high-capital industries, have increased dramatically. In particular, the oil industry requires performance appraisal systems for better management of oil and gas production assets. Oil and gas producers and regulatory authorities have taken initiatives in this area. The need for a better insight into important business processes in line with the business goals appears to have helped redefine the business impact of maintenance operations.

- In response to the growing demands of oil and gas industries, a joint industry project for the development and implementation of MRO indicators in the petroleum industry seems essential for asset and maintenance management centers. To address the alienation of technical and maintenance outsourcing in oil and gas industries, we aimed to establish a relationship between oil and gas businesses, oil and gas production assets, and maintenance and repair operations through outsourcing. The basic assumption was that the portfolio of oil and gas industries played a significant role in the trade success of any organization with respect to important factors; this portfolio is the basis for redefining the purpose of maintenance. It is also the starting point for the systematic development of operations and maintenance architecture;

- There are few studies on repair and maintenance outsourcing in gas refineries, and only several reliable papers have been published regarding its impact on the equipment profitability, efficiency, and effectiveness. Accordingly, the present study aimed to identify factors, affecting maintenance outsourcing in a cause-and-effect model by defining different scenarios. For this purpose, we introduced the nodes, reviewed the literature, and interviewed experts to identify important goals. First, the indices influencing repair and maintenance outsourcing in previous studies were evaluated, and the effects of these indices on the profitability, efficacy, and effectiveness of the equipment were investigated. Next, based on the collected information, the stock variables (i.e., profitability, efficacy, and effectiveness of equipment) were defined in the system dynamics, and different strategies and scenarios were designed.

- Step 2. Identify the variables: In the first step, the key variables were extracted using the data presented in the reviewed studies. In the second step, the experts' opinions were extracted. Table 1 presents the key variables used in modeling the research problem.

- Step 3. Create the system dynamics model: The behavior of the model over time was specified by the reference pattern and displayed as a figure, graph, or table. The improved functional ground state is illustrated in Figure 2. The optimal conditions could be determined when the profitability, efficiency, and effectiveness of the equipment were at maximum lev- 


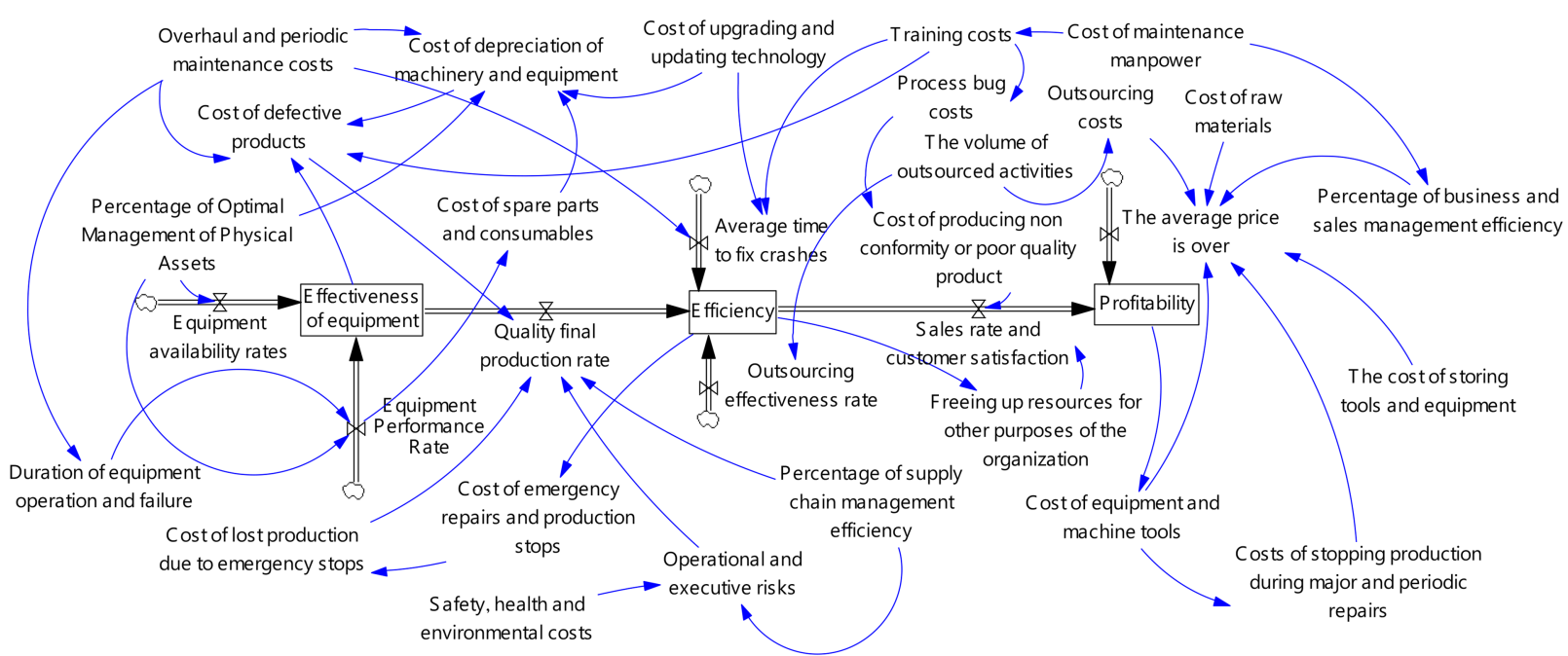

Figure 2. Research problem model.

els; this was achieved by considering the subsequent changes in the values of influential variables in the model.

- Modeling of time horizon: In most empirical studies on diversification, a yield of $3-5$ years was identified. The system dynamics modeling has been built over 60 months to investigate the dynamics of collaboration among organizations. In the present study, based on the expert opinion and research background, a 60-month (five-year) time horizon was used to evaluate the feedback performance;

- Formulation of dynamics hypothesis: A suitable dynamics hypothesis and a well-defined underlying mechanism can provide enough information to rate equations for starting the system and then, the next stage of the modeling process can be targeted. After interviewing experts and reviewing the articles, it was found that some criteria were more influential. Some variables with similar effects were eliminated to simplify the model. It was concluded that the effectiveness, efficiency, and profitability of equipment could be achieved by planning to change or confront the changes of the following variables depending on their impact on the goals: costs of overhaul, repair, and preventive maintenance; costs of upgrading and updating the technology; maintenance personnel costs; the stock price index; the equipment and machinery price index; the volume of outsourced activities; the efficiency percentage of optimal physical asset management; the efficiency percentage of supply chain management; costs of HSE; and the initial input price of the plant;

- Modeling of boundary setting: Generally, all models have certain limitations; therefore, setting boundaries for the system is of particular importance. All-important members of the system that interact with other members should be identified as internal variables. All components that affect the system but are not influenced by it are external variables, and other system components must be eliminated. The authorities responsible for implementing the system believe that the existing limitations confine the model. These individuals have a systematic view, which successfully reflects the ability to observe all existing conditions or concepts that interact with the environment. A dynamic system helps extend the boundaries of conceptual models. Table 1 presents the key variables in modeling the research problem;

- Research loops: In the current study, the cause-and-effect relationships and their conversion to flow diagrams were used for modeling and illustrating the relationships between the influential variables. As mentioned earlier, the variables presented in Table 1 were examined, and the cause-and-effect relationships, as well as the flow diagrams of stock and auxiliary variables, were assessed and shown as the equipment efficacy, effectiveness, and profitability in Figures 3-5.

According to a study by $\mathrm{Ou}$ et al. [41], the equipment availability (ease of access) and equipment efficiency rates influence the effectiveness of equipment. According to a study by Fekri and Avakh [43], the efficiency percentage of optimal physical asset management affects the availability rate, the efficiency rate, and the depreciation expense of equipment and machinery. Therefore, easier access to the equipment is associated with the higher efficacy percentage of optimal physical asset management and the more accurate location of the 


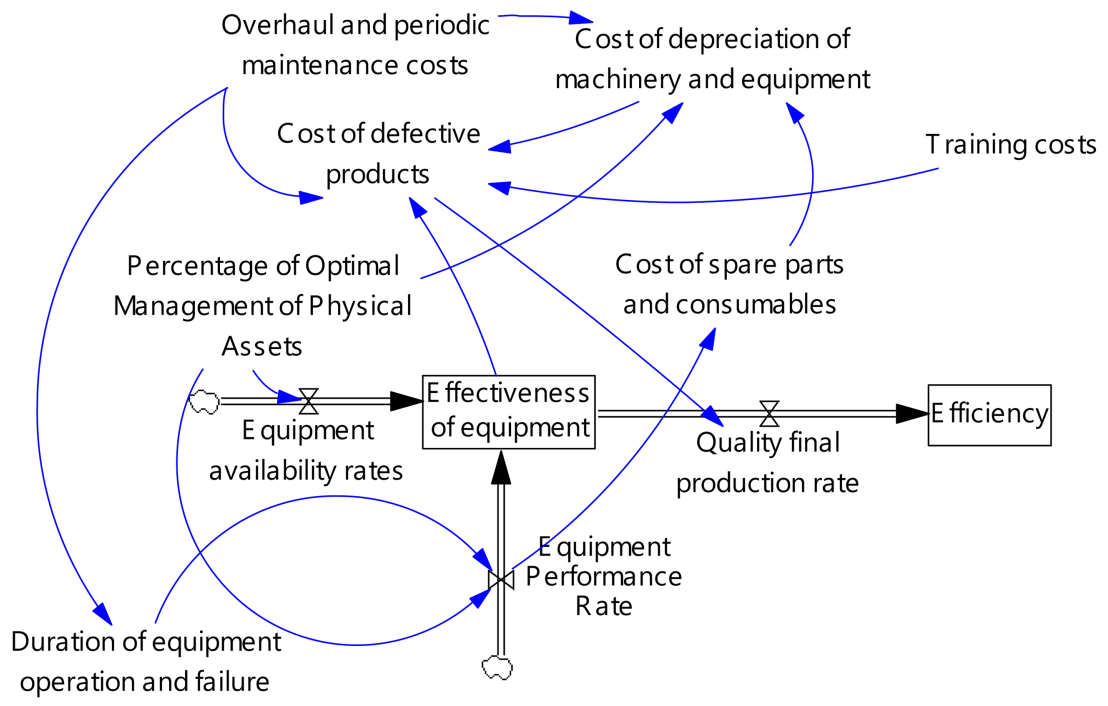

Figure 3. Flowchart of the state variable of the equipment effectiveness.

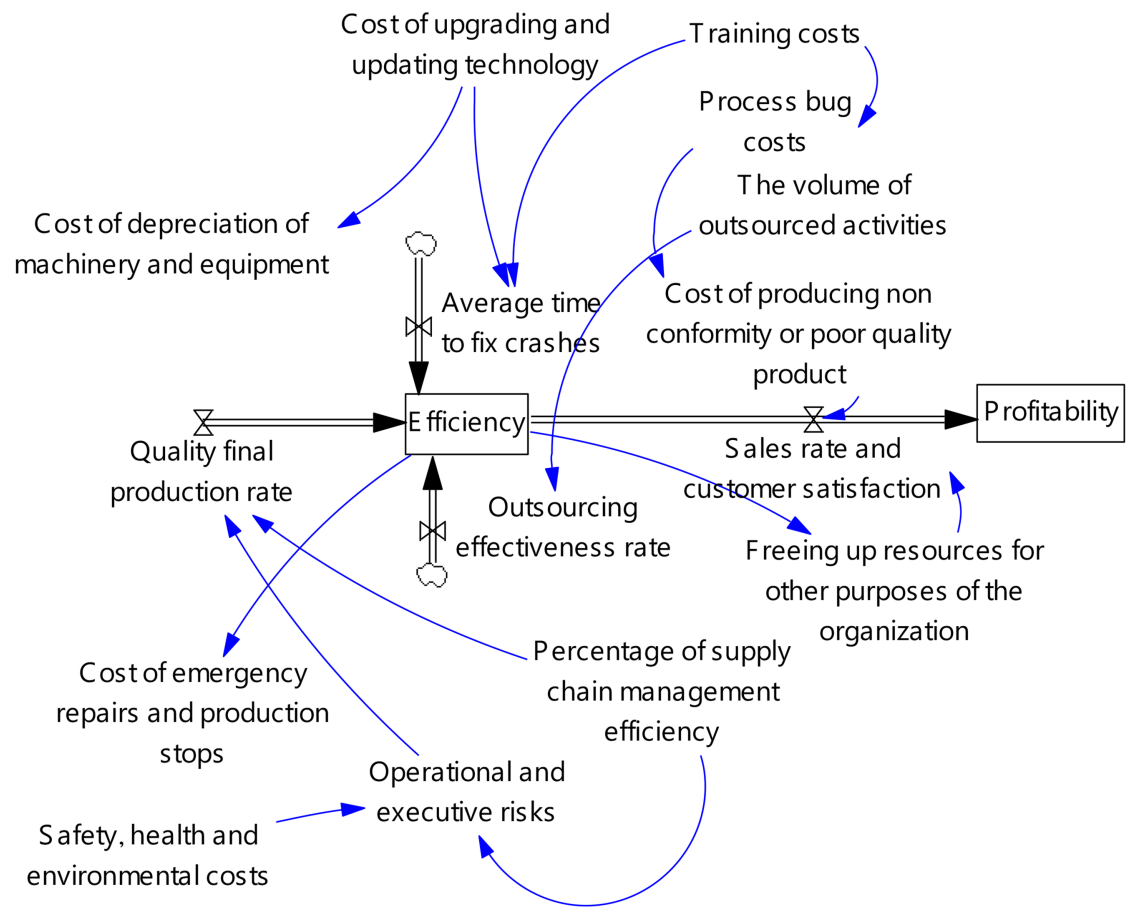

Figure 4. Flowchart of efficacy variable.

equipment. Also, depreciation of physical assets can be reduced by correct management of their usage and maintenance.

On the other hand, depreciation of equipment, besides management, is affected by the cost of overhaul, repair, and preventive maintenance. In other words, more accurate overhaul, repair, and preventive maintenance reduce the depreciation of equipment. Likewise, overhaul, repair, and preventive maintenance affect the equipment life, as well as the failure and cost of defective products. According to previous studies, the purpose of overhaul, repair, and preventive maintenance is to extend the equipment life and reduce equipment failure. The healthier the equipment, the fewer the defective products. On the other hand, the efficiency rate of equipment affects the cost of spare parts and consumables. In other words, the higher the equipment efficiency is, the fewer the spare parts and consumables will be needed. Another influential variable in these loops is the cost of training. It has been shown that more qualified and trained staff can produce less defective products and increase the rate of production accuracy. The outputs of the 


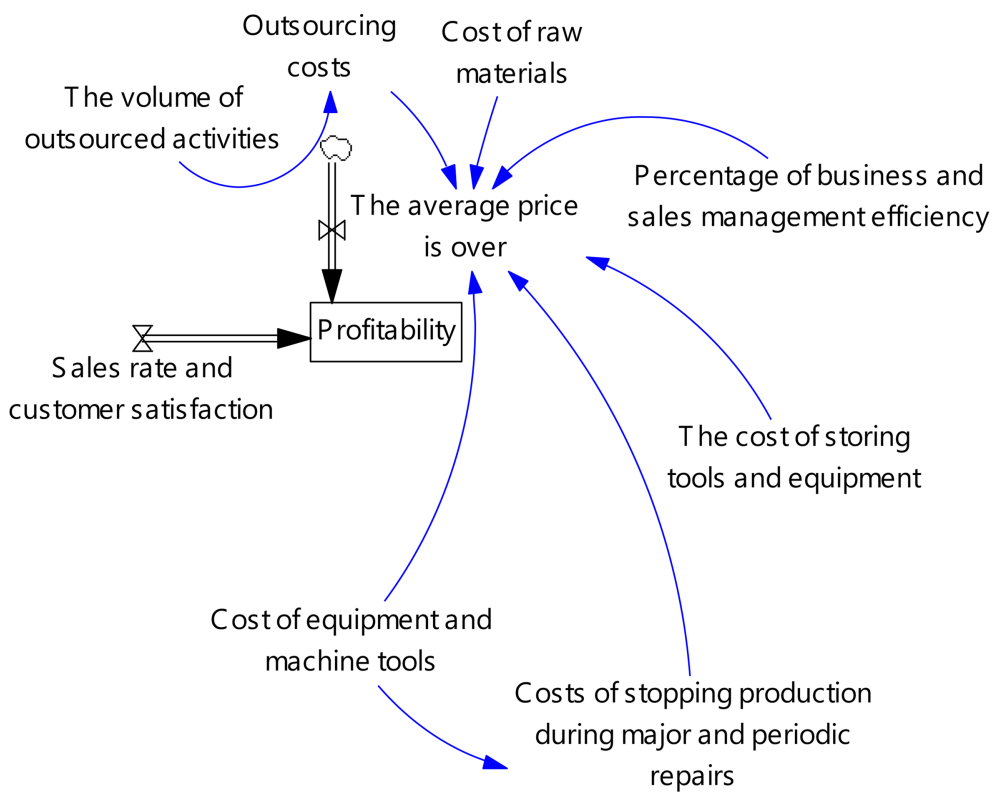

Figure 5. Flowchart for profitability variable.

stock variable include the equipment effectiveness, sales rate, and customer satisfaction. Moreover, use of more efficient equipment increases the quality of products and consequently, enhances the product quality and customer satisfaction. The stock and auxiliary variables, as well as the rate of variables, are shown in Figure 4.

Moreover, Idris and Nayan [44] found that many variables affected the equipment efficacy, including the production quality, training, technology, identification of operational risks, and environmental issues, some of which were included in the current study. According to previous research, higher equipment efficacy is associated with higher customer satisfaction. Also, repair and maintenance staff, who are adequately trained, can reduce the average time to repair and increase the equipment efficacy. Efficacy can be also improved by identifying and preventing the operational risk. Regarding HSE, Idris and Nayan [44] believed that a healthier and safer environment was correlated with greater workforce productivity and increased efficacy of the organization.

In terms of technology, it is also clear that the use of appropriate technologies can reduce the average time to repair. In other words, a shorter average time to repair is associated with greater efficacy gain due to the rapid addition of faulty equipment to the production cycle. The goal of outsourcing is to reduce the costs and increase efficacy; therefore, the greater the effectiveness of outsourcing is, the greater the efficiency will be. In addition, process bugs affect the production of defective products. In other words, if the manufacturing or any other related process, such as maintenance or repair, fails, the risk of producing defective products increases, which in turn affects customer satisfaction. However, these bugs can be mitigated via proper staff training.

By increasing the efficacy of supply chain management, the operational and executive risks can be identified better due to a rigorous process oversight, and the quality of final products can be enhanced. Regarding the volume of outsourcing, it was observed that the efficacy loops also influenced the effectiveness rate of outsourcing; obviously, the higher this volume is, the more difficult it will be to manage. Furthermore, regarding the output variables, as efficacy increases, the cost of emergency repairs and stoppage is reduced, as high efficiency ensures timely repair and proper use of equipment; consequently, such events are reduced. In addition, higher efficacy is associated with the greater allocation of resources to other goals of the organization. The profitability loops are presented in Figure 5 .

Nomikos and Doctor [45] believed that the concept of profit was derived from subtracting the expenses from revenue. In this system, profitability is derived by subtracting the revenue from the variables of sales rate, customer satisfaction, the price of equipment and machinery, the cost of production stoppage at the time of overhaul, the price of stock, the initial input price of the plant, and the cost of outsourcing, all of which are conceptually called the "average product cost", influencing profitability.

Other effective variables in these loops include the efficiency percentage of business management, sales, and outsourcing volume. Overall, the effectiveness of business management and sales affects the costs, as the costs of business teams are of great 
significance. In addition, the more skilled the team, the higher the sales rate and customer satisfaction. The volume of outsourcing also has a direct impact on its cost, as an increase in the outsourcing volume increases the costs, as well.

- Steps 4 and 5: Implementation and validation of the system dynamics model: Sterman, citing Coyle and Exelby [46], presented a set of tests for model validation. The validity of the model designed in the current study was assessed using the following tests:

1. Boundary adequacy test: The effects of variables on one another were confirmed based on previous research and expert approval, besides eliminating the variables from the model one at a time, as shown in the following section. Figure 6 shows the impact of eliminating the variable of "efficacy percentage of business management and sales". This variable was found to have a significant effect on profitability. By eliminating this variable, the profitability criterion remained almost constant and did not increase over five years;

Figure 7 shows the effect of eliminating the variable of "volume of outsourcing" on the

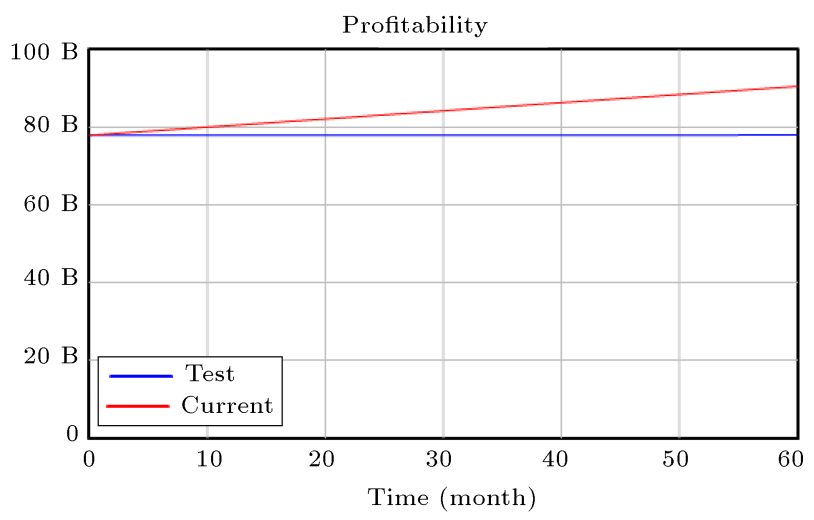

Figure 6. Effect of the elimination of efficiency percentage of business management and sales on profitability.

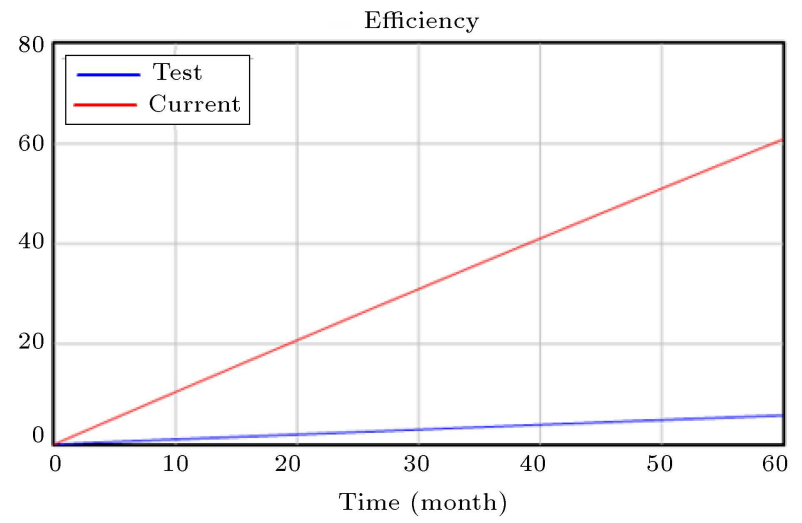

Figure 7. Effect of the elimination of the volume of outsourcing on the efficacy variable.

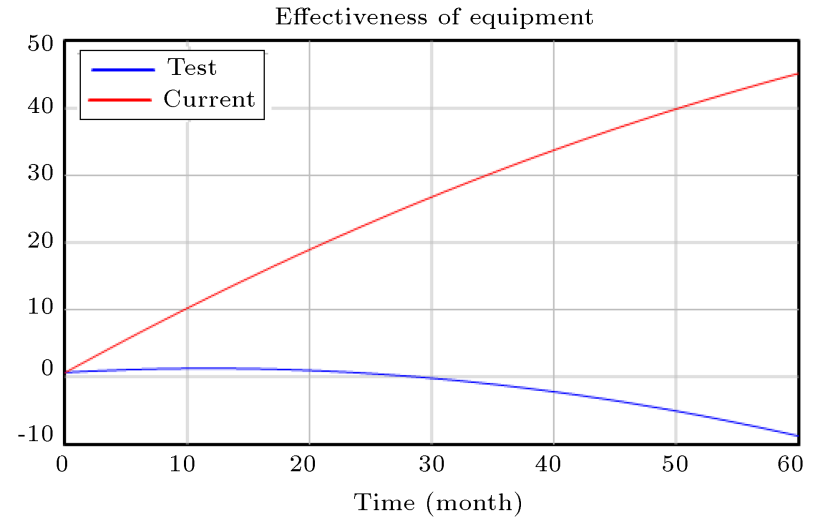

Figure 8. Effect of elimination of "service time and failure" factor on equipment effectiveness.

efficacy variable. According to Figure 8, lack of attention to the volume of outsourcing in the long run reduces the efficacy to zero (efficacy is expressed as percentage). Figure 8 presents the effect of eliminating the variable of "service life and failure" on the effectiveness of the equipment. We determined the extent to which the elimination of outsourcing volume could affect the effectiveness of equipment and reduce it (effectiveness is expressed as percentage);

2. Structure verification test: Structural verification means that the actual relationships related to the research goals are sufficiently included in the model. Since the model equations were written in Vensim software in the current study, the model equations were verified (Figure 9).

3. Parameter assessment test: The model parameters and variables were assessed using trial and error through comparative analysis with the reference model and review of previous studies; they were finally confirmed after expert consultation;

4. Boundary conditions test: This test examines the behavior of the model when the model inputs are in the boundary condition, that is, when they are at their minimum or maximum levels. In the present study, we considered whether the model was stable under such conditions. In this test, the variables were examined in the infinite state (i.e., maximum and minimum).

Condition 1: The equipment availability rate reaches zero (Figure 10). If the equipment availability rate drops too low, the equipment effectiveness is reduced by almost one-third after five years. In other words, the lower the availability rate is, the lower the efficiency of the equipment will be;

Condition 2: The average time to repair is at maximum (Figure 11). If the average time 


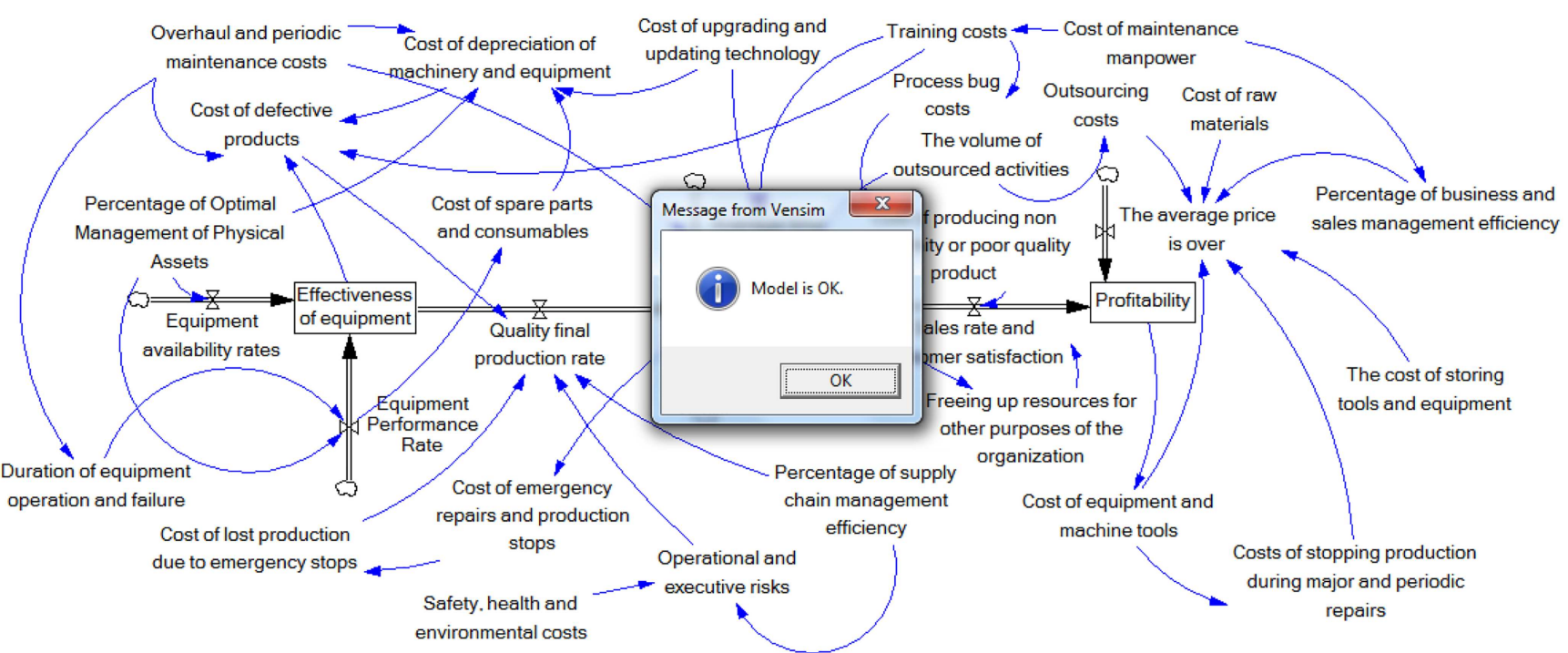

Figure 9. Verification of equations structure in Vensim software.

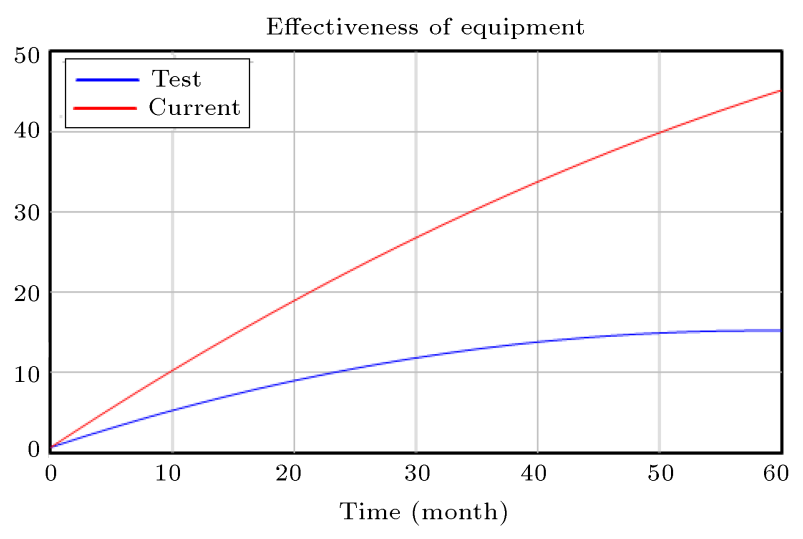

Figure 10. Model behavior when the equipment availability rate reaches zero.

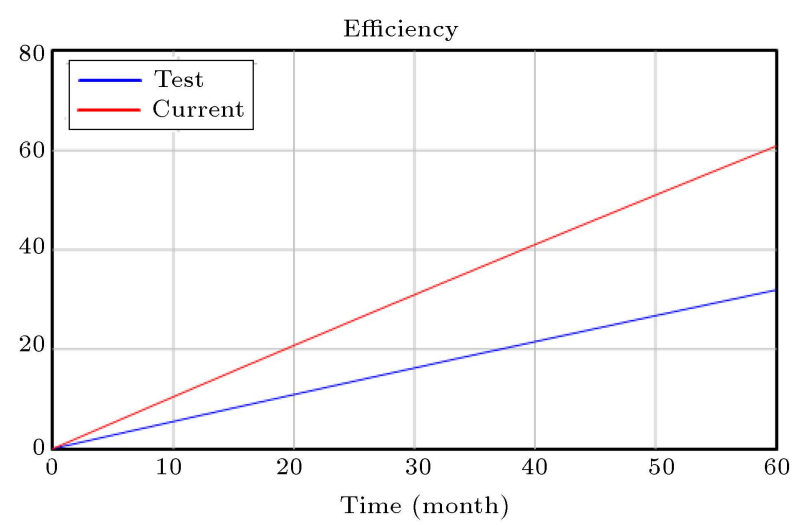

Figure 11. Model behavior in the boundary states of the average time to repair.

to repair tends to go upward, as shown in Figure 11, the efficacy strongly drops;

Condition 3: The average cost is at minimum (Figure 12). As shown in Figure 12, if the average cost reaches its minimum, the prof-

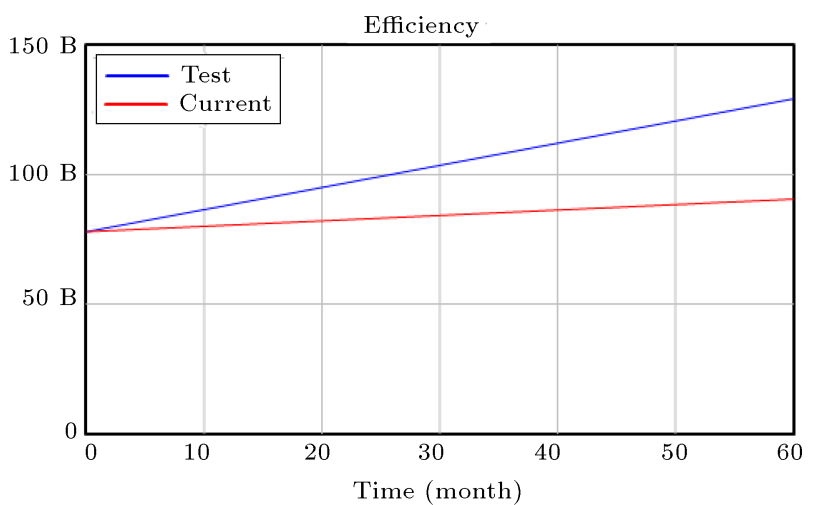

Figure 12. Model behavior in boundary conditions of average cost.

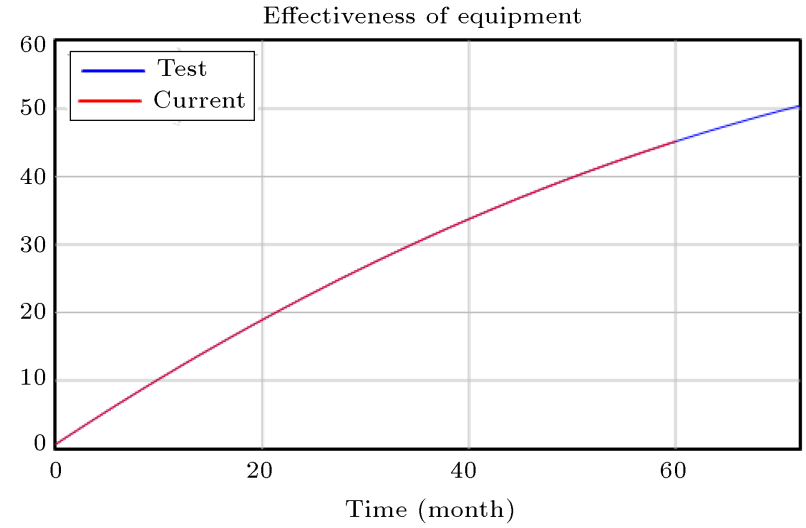

Figure 13. Model outputs at 60 - and 72 -month intervals.

itability will rise sharply, since it both directly and inversely depends on the average cost.

5. Integration error test: This test represents the sensitivity of the model results to the selected interval. In the current study, the 60-month interval was changed to a 72 -month interval, as shown in Figure 13. No changes were observed 


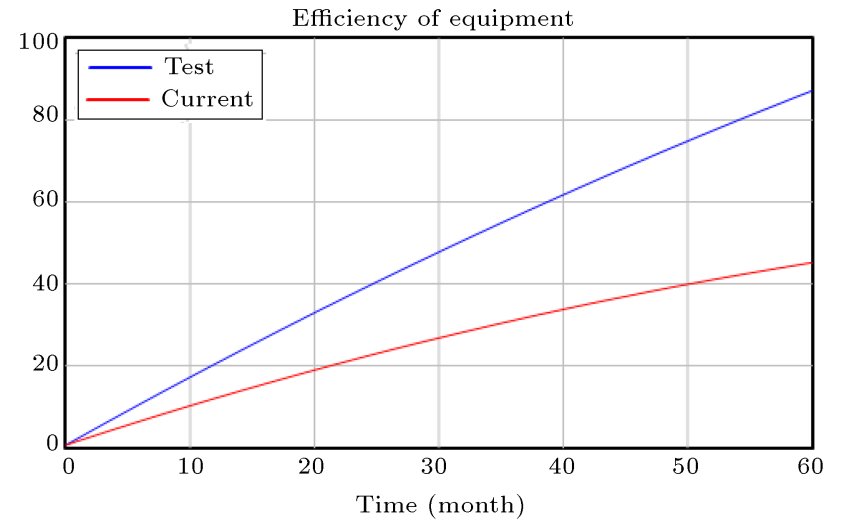

Figure 14. Increased effectiveness of equipment.

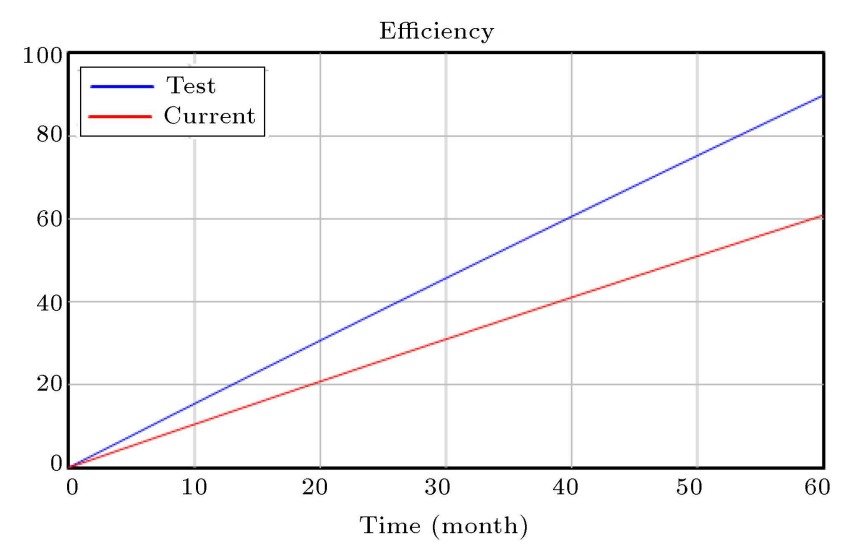

Figure 15. Increased efficacy.

in the model behavior in both 60- and 72-month intervals, and it was found that factors influencing performance, if controlled, could improve performance;

6. Behavior reproduction test: This test determines whether the system can reproduce the actual conditions. Based on previous studies, it considers factors affecting the three main variables considered in the current study, that is, the equipment effectiveness, efficiency, and profitability. Therefore, this model can predict the behavior of the system. As shown in Figures 1416, by controlling the equipment availability rate, the average time to repair, and the average cost, it is possible to increase the equipment effectiveness, efficacy, and profitability, respectively. However, there are many factors involved in improving performance and they require more time to coordinate;

- Step 6: Analysis of the results and presentation of the scenario: In the final step, according to the results of the model and its validity and effectiveness, five different scenarios were designed and implemented by changing the model parameters. Depending on these scenarios, different strategies can be defined and implemented. For this purpose, based

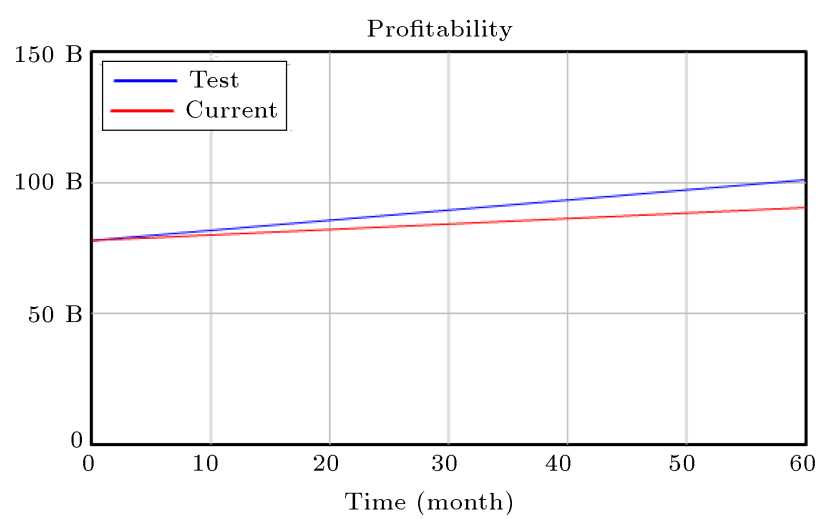

Figure 16. Increased profitability.

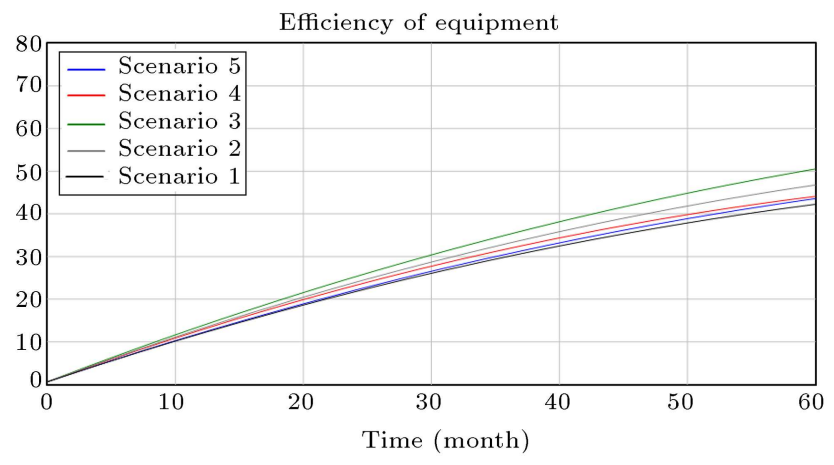

Figure 17. Different scenarios in state variable of equipment effectiveness.

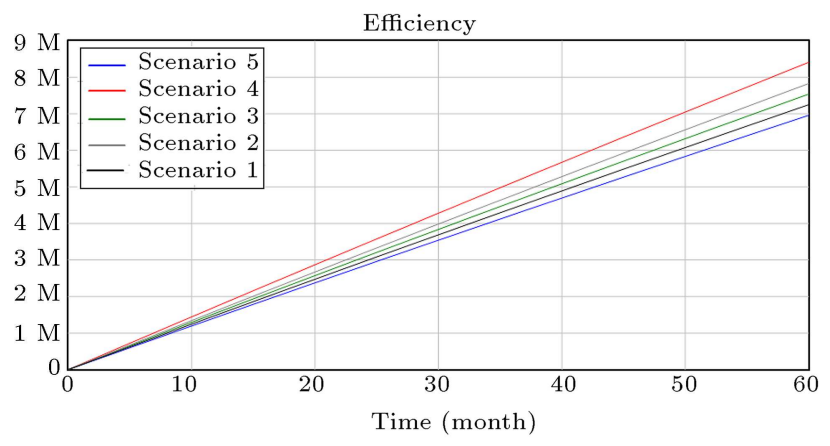

Figure 18. Different scenarios in the state variable of efficacy.

on the experts' opinions and the values measured in studies published in scientific journals, different values were considered for the variables, and five scenarios were simulated and defined. The variables and the values corresponding to the scenarios are shown in Table 2. Figures 17-19 illustrate the scenarios for the three variables investigated in this study, that is, the equipment effectiveness, efficacy, and profitability. These five scenarios were designed based on the variables controlled by the organization and uncontrollable variables in the environment.

The values presented in Table 2 represent the percentage of increase in variables in the scenarios.

- Scenario 1: The overhaul, repair, and preventive 
Table 2. The research scenarios.

\begin{tabular}{|c|c|c|c|c|c|}
\hline Variable & $\begin{array}{c}\text { Scenario } \\
1 \\
\end{array}$ & $\begin{array}{c}\text { Scenario } \\
2\end{array}$ & $\begin{array}{c}\text { Scenario } \\
3\end{array}$ & $\begin{array}{c}\text { Scenario } \\
4\end{array}$ & $\begin{array}{c}\text { Scenario } \\
5\end{array}$ \\
\hline Overhaul, recurrent, and preventive maintenance costs & 10 & 12 & 8 & 13 & 15 \\
\hline Technology upgrading and updating costs & 8 & 7 & 9 & 10 & 5 \\
\hline Maintenance personnel costs & 15 & 10 & 13 & 17 & 20 \\
\hline Stock price & 5 & 9 & 7 & 10 & 8 \\
\hline Equipment and machinery price & 10 & 7 & 10 & 12 & 15 \\
\hline Outsourcing volume & 8 & 10 & 13 & 15 & 17 \\
\hline Efficacy percentage of optimal management of physical assets & 12 & 17 & 9 & 15 & 10 \\
\hline Efficacy percentage of supply chain management & 10 & 11 & 9 & 13 & 7 \\
\hline HSE costs & 7 & 10 & 9 & 11 & 10 \\
\hline The initial input price of the plant & 3 & 5 & 6 & 7 & 5 \\
\hline
\end{tabular}

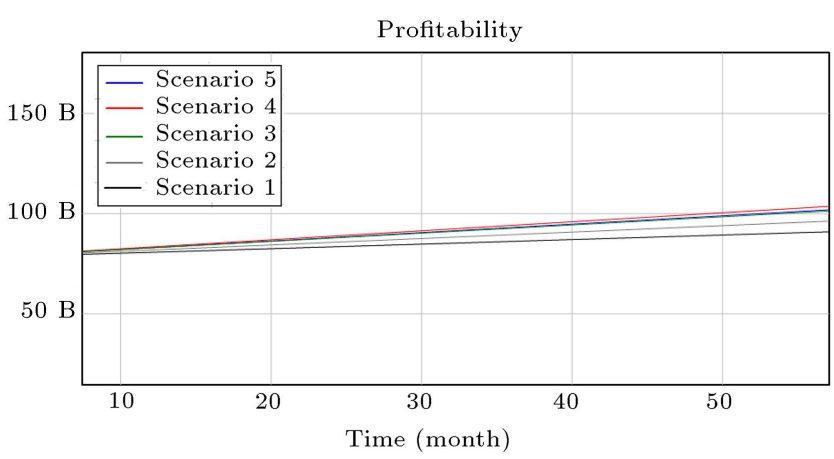

Figure 19. Different scenarios in the state variable of profitability.

maintenance costs increased by $10 \%$, which in turn affected the rate of growth in the depreciation expenses of machinery and equipment, the price of defective products, and the average time to repair. Also, the cost of upgrading and updating the technology increased by $8 \%$, which could also affect the cost of equipment and machinery depreciation and the average time to repair. Moreover, the maintenance personnel cost increased by $15 \%$, which in turn affected the training costs and the efficiency percentage of business management and sales. On the other hand, the stock price index was reduced by $5 \%$, indicating its effect on the average cost. A $10 \%$ increase in the equipment and machinery price index increased the use of a new technology, which in turn influenced the average and stoppage costs in overhaul and repair processes. On the other hand, the outsourcing volume increased by $8 \%$; the efficiency percentage of optimal physical asset management increased by $12 \%$; the efficiency percentage of supply chain management increased by $10 \%$; the HSE costs increased by $7 \%$; and the initial input price increased by $3 \%$;

- Scenario 2: The overhaul, repair, and preventive maintenance costs increased by $12 \%$; the cost of upgrading and updating the technology increased by $7 \%$; the maintenance personnel costs increased by $10 \%$; the stock price index increased by $9 \%$; the equipment and machinery price index increased by $7 \%$; the outsourcing volume increased by $10 \%$; the efficacy percentage of optimal physical asset management increased by $17 \%$; the efficiency percentage of supply chain management increased by $11 \%$; the HSE costs increased by $10 \%$; and the initial input price increased by $5 \%$;

- Scenario 3: The overhaul, repair, and preventive maintenance costs increased by $8 \%$; the cost of upgrading and updating the technology increased by $9 \%$; the maintenance personnel costs increased by $13 \%$; the stock price index increased by $7 \%$; the equipment and machinery price index increased by $10 \%$; the outsourcing volume increased by $13 \%$; the efficiency percentage of optimal physical asset management increased by $9 \%$; the efficiency percentage of supply chain management increased by $9 \%$; the HSE costs increased by $9 \%$; and the initial input price increased by $6 \%$;

- Scenario 4: The costs of overhaul, repair, and preventive maintenance increased by $13 \%$; the cost of upgrading and updating the technology increased by $10 \%$; the maintenance personnel costs increased by $17 \%$; the stock price index increased by $10 \%$; the equipment and machinery price index increased by $12 \%$; the outsourcing volume increased by $15 \%$; the efficiency percentage of optimal physical asset management increased by $15 \%$; the efficiency percentage of supply chain management increased by $13 \%$; the HSE costs increased by $11 \%$; and the initial input price increased by $7 \%$;

- Scenario 5: The overhaul, repair, and preventive maintenance costs increased by $15 \%$; the cost of upgrading and updating the technology increased by $5 \%$; the maintenance personnel costs increased 
by $20 \%$; the stock price index increased by $8 \%$; the equipment and machinery price index increased by $15 \%$; the outsourcing volume increased by $17 \%$; the efficacy percentage of optimal physical asset management increased by $10 \%$; the efficacy percentage of supply chain management increased by $7 \%$; the HSE costs increased by 10\%; and the initial input price increased by $5 \%$.

\subsection{Discussion}

Based on these scenarios, the model was reimplemented and the stock variable changes in these scenarios were examined with respect to the changes in the variables (Figures 17-19). In these figures, the results of model simulation were plotted using Scenario 5, while Scenario 4 showed the best performance regarding the efficacy and profitability variables when the cost of overhaul, repair, and preventive maintenance increased by $13 \%$; the cost of upgrading and updating the technology increased by $10 \%$; the maintenance personnel costs increased by $17 \%$; the stock price index increased by $10 \%$; the equipment and machinery price index increased by $12 \%$; the outsourcing volume increased by $15 \%$; the efficacy percentage of optimal physical asset management increased by $15 \%$; the efficacy percentage of supply chain management increased by $13 \%$; the HSE costs increased by $11 \%$; and the initial input price increased by $7 \%$. Scenario 3 also showed the best performance regarding the equipment effectiveness, as the overhaul, repair, and preventive maintenance costs increased by $8 \%$; the costs of upgrading and updating the technology increased by $9 \%$; the maintenance personnel costs increased by $13 \%$; the stock price index increased by $7 \%$; the equipment and machinery price index increased by $10 \%$; the outsourcing volume increased by $13 \%$; the efficacy percentage of optimal physical asset management increased by $9 \%$; the efficacy percentage of supply chain management increased by $9 \%$; the HSE costs increased by $9 \%$; and the initial input price increased by $6 \%$.

According to the results of these scenarios, we should determine whether the rate of increase in profitability and productivity in Scenario 4 and the strategies used to achieve the desired values of variables in this scenario are economically more favorable than Scenario 3. To overcome this problem, managers need to analyze the decision-making problem according to the conditions of the refinery. However, future studies need to evaluate the decision-making model and implement appropriate strategies.

\section{Conclusion}

There are many reasons for outsourcing. Outsourcing service providers often promise lower costs and higher reliability in purchases. A contract should rely on guaranteed reliability and lower costs. There are successful examples of maintenance outsourcing, which can be suitable for many organizations. However, they have only considered maintenance outsourcing, without paying attention to reliability motives. Outsourcing contracts, which are based on total maintenance outsourcing, often focus on reducing the maintenance costs rather than improving maintenance. Also, reasoning often depends on cost savings that can be achieved. Therefore, service providers often need more appropriate work management systems to reduce the total costs of labor and management. Today, this is considered a major challenge due to the shortage of skilled workforce. Considering the need to investigate these variables to reach the desired equipment effectiveness, efficiency, and profitability in maintenance outsourcing, the effects of variables on one another were considered in the dynamic system approach, besides factors affecting the equipment efficiency, effectiveness, and profitability. In the current study, these factors were investigated using the dynamic system approach, and their relationships were addressed. Next, a model was designed and evaluated, and five different scenarios were established; the applicable ones were examined by assuming changes in the main variables, affecting the stock variables of the model.

After designing different scenarios, by approximating the values of variables in Table 2 to the values of Scenario 4, the efficacy variable exhibited an upward trend over five years; profitability was also at its maximum level. In other words, by changing the values of variables to the levels presented in Scenario 4, the products purchased by the consumer were the most profitable ones. On the other hand, the equipment effectiveness reached its optimal level in Scenario 3. Therefore, managers should approximate the values of variables to those of Scenario 4 to maximize profit. Given the heavy capital spent on equipment, to bring the values of the variables closer to the values of Scenario 3 and to increase the effectiveness of equipment, managers should be less concerned about the profit and consider the health of equipment. Based on the results of the present study, users can achieve their desired goals in Scenarios 4 and 5 by considering different solutions and plans.

As shown in Figure 16, if Scenario 3 is preferred to Scenario 4 , the effectiveness of equipment will increase by about $10 \%$ in Scenario 3, relative to Scenario 4, whereas if Scenario 4 is implemented according to Figures 17 and 18, productivity increases by about $12 \%$ and profitability increases by about 10 billion units. These results indicate that managers should select a scenario in line with the cost of equipment, besides the impact of equipment on the cost of breakdowns and repairs. Also, when uncontrolled and external variables 
approach the states defined in these scenarios, users can respond to changes by changing their strategy. In future studies, researchers must develop strategies to reach the desirable values of variables and provide effective management strategies. Moreover, crisis management strategies can be explored when imposed and unmanaged variables are changed by the organization.

\section{References}

1. Suweero, K., Moungnoi, W., and Charoenngam, C. "Outsourcing decision factors of building operation and maintenance services in the commercial sector", Prop. Manag., 35(3), pp. 254-274 (2017).

2. Hendalianpour, A., Fakhrabadi, M., Sangari, M.S., et al. "A combined benders decomposition and lagrangian relaxation algorithm for optimizing a multi-product, multi-level omni-channel distribution system", Sharif University of Technology, Scientia Iranica, 29(1), pp. 355-371 (2022).

3. Rodrigues, D. and Lavorato, P. "Maintenance, Repair and Overhaul (MRO) fundamentals and strategies: An aeronautical industry overview", Int. J. Comput. Appl., 135(12), pp. 21-29 (2016).

4. Hendalianpour, A. "Optimal lot-size and price of perishable goods: A novel game-theoretic model using double interval grey numbers", Comput. Ind. Eng., 149, p. 106780 (Nov. 2020).

5. Murthy, D.N.P., Karim, M.R., and Ahmadi, A. "Data management in maintenance outsourcing", Reliab. Eng. Syst. Saf., 142, pp. 100-110 (2015).

6. Hendalianpour, A., Razmi, J., and Rameshi, A. "Applying decision tree models to SMEs: A statisticsbased model for customer relationship management", Manag. Sci. Lett., 6(7), pp. 509-520 (2016).

7. Salmasnia, A., Hajihosseini, Z., Namdar, M., et al. "A joint determination of production cycle length, maintenance policy, and control chart parameters considering time value of money under stochastic shift size", Sci. Iran., 27, pp. 22-29 (Jul. 2020).

8. Pascual, R., Santelices, G., Liao, H., et al. "Channel coordination on fixed-term maintenance outsourcing contracts", IIE Transactions, 48(7), pp. 651-660 (2016).

9. Alabyev, V., Kruk, M., Bazhina, T., et al. "Economic efficiency of the application of artificial air cooling for normalization of thermal conditions in oil mines", Scientia Iranica, 27(3), pp. 1606-1615 (2020).

10. Salari, M. and Khamooshi, H.A. "better project performance prediction model using fuzzy time series and data envelopment analysis", Journal of the Operational Research Society, 67(10), pp. 1274-1287 (2016).

11. Feylizadeh, M., Hendalianpour, A., and Bagherpour, M.A. "Fuzzy neural network to estimate at completion costs of construction projects", International Journal of Industrial Engineering Computations, 3(3), pp. 477484 (2012).
12. Stenström, C., Norrbin, P., Parida, A., et al. "Preventive and corrective maintenance-cost comparison and cost-benefit analysis", Structure and Infrastructure Engineering, 12(5), pp. 603-617 (2016).

13. Krstić, H. and Marenjak, S. "Model procjene troškova održavanja i uporabe sveučilišnih građevina", Tehnički vjesnik, 24(Supplement 1), pp. 193-200 (2017).

14. Lundgren, C., Skoogh, A., and Bokrantz, J. "Quantifying the effects of maintenance-a literature review of maintenance models", Procedia CIRP, 72, pp. 13051310 (2018).

15. Marais, K.B. and Saleh, J.H. "Beyond its cost, the value of maintenance: an analytical framework for capturing its net present value", Reliability Engineering \& System Safety, 94(2), pp. 644-657 (2009).

16. Kumar, U., Parida, A., Duffuaa, S.O., et al. "Performance indicators and terminology for value driven maintenance", Journal of Quality in Maintenance Engineering, 86, pp. 67-72 (2013).

17. Diallo, C., Venkatadri, U., Khatab, A., et al. "State of the art review of quality, reliability and maintenance issues in closed-loop supply chains with remanufacturing", International Journal of Production Research, 55(5), pp. 1277-1296 (2017).

18. Fraser, K., Hvolby, H.H., and Tseng, T.L.B. "Maintenance management models: a study of the published literature to identify empirical evidence", International Journal of Quality \& Reliability Management, 32(6), pp. 635-664 (2015).

19. Al-Najjar, B. "The lack of maintenance and not maintenance which costs: A model to describe and quantify the impact of vibration-based maintenance on company's business", Int. J. Prod. Econ., 107(1), pp. 260-273 (2007).

20. Sharma, A., Yadava, G.S., and Deshmukh, S.G. "A literature review and future perspectives on maintenance optimization", Journal of Quality in Maintenance Engineering, 17(1), pp. 5-25 (2011).

21. Goodfellow, J.W. "Applying reliability centered maintenance (RCM) to overhead electric utility distribution systems", In Proceedings of the IEEE Power Engineering Society Transmission and Distribution Conference, 1, pp. 566-569 (2000).

22. Ross, A.M., Rasor, B., and Moleski, H. "How reliability centered maintenance (RCM) will affect system reliability", In Proceedings of the IEEE Power Engineering Society Transmission and Distribution Conference, pp. 1-9 (2018).

23. Afzali, P., Keynia, F., and Rashidinejad, M. "A new model for reliability-centered maintenance prioritisation of distribution feeders", Energy, 171, pp. 701-709 (2019).

24. Rafiei, M., Khooban, M.-H., Afshari-Igder, M., et al. "A novel approach to overcome the limitations of reliability centered maintenance implementation on the smart grid distance protection system", IEEE Trans. Circuits Syst. II Express Briefs, 67, pp. 14-21 (2019). 
25. Cheng, M.Y., Chiu, Y.F., Chiu, C.K., et al. "Riskbased maintenance strategy for deteriorating bridges using a hybrid computational intelligence technique: a case study", Struct. Infrastruct. Eng., 15, pp. 334-350 (2019).

26. Özkan, B.E. and Bulkan, S. "Obsolescence management for sustainment-dominated military systems", in Operations Research for Military Organizations, 97, pp. 205-224 (2019).

27. Nielsen, J.S., Tcherniak, D., and Ulriksen, M.D. "A case study on risk-based maintenance of wind turbine blades with structural health monitoring", Structure and Infrastructure Engineering, 104, pp. 1-17 (2020).

28. Irawan, C.A., Eskandarpour, M., Ouelhadj, D., et al. "Simulation-based optimisation for stochastic maintenance routing in an offshore wind farm", Eur. J. Oper. Res., 289(3), pp. 912-926 (2019).

29. Wakiru, J.M., Pintelon, L., Muchiri, P.N., et al. "A simulation-based optimization approach evaluating maintenance and spare parts demand interaction effects", Int. J. Prod. Econ., 208, pp. 329-342 (2019).

30. Horvath, K., Eisenberg, D., Stone, R., et al. "Paternal age and transgenerational telomere length maintenance: A simulation model", Sci. Rep., 9, pp. 1-8 (2019).

31. Packianather, M.S., Michael, S., Sajith S., et al. "Predictive maintenance in a manufacturing environment through FIT manufacturing and discrete event simulation", In 2018 World Automation Congress (WAC), pp. 1-6, IEEE (2018).

32. Ganji, F., Moslehi, G., and Jeddi, B.G. "Minimizing maximum earliness in single-machine scheduling with flexible maintenance time", Sci. Iran., 24(4), pp. 20822094 (2017).

33. Qin, Y., Zhang, J.H., Chan, F.T.S., et al. "A two-stage optimization approach for aircraft hangar maintenance planning and staff assignment problems under MRO outsourcing mode", Comput. Ind. Eng., 146, p. 106607 (2020).

34. Chen, S.-H., Kuo, Y., and Lin, J.-K. "Using Mahalanobis distance and decision tree to analyze abnormal patterns of behavior in a maintenance outsourcing process-a case study", J. Qual. Maint. Eng., 96, pp. 102-119 (2020).

35. Mokhtari, H. and Asadkhani, J. "Extended economic production quantity models with preventive maintenance", Sci. Iran., 27(6), pp. 3253-3264 (2019).

36. Tai, A.H. "A model for continuously degrading systems with outsourcing maintenance service", Int. J. Math. Oper. Res., 13, pp. 178-201 (2018).

37. Bağan, H. and Gerede, E. "Use of a nominal group technique in the exploration of safety hazards arising from the outsourcing of aircraft maintenance", Saf. Sci., 118, pp. 795-804 (2019).
38. Nabavi, E., Daniell, K.A., and Najafi, H. "Boundary matters: the potential of system dynamics to support sustainability?", J. Clean. Prod., 140, pp. 312-323 (2017).

39. Sosnowska, J., Kuppens, P., De Fruyt, F., et al. "A dynamic systems approach to personality: The Personality Dynamics (PersDyn) model", Pers. Individ. Dif., 144, pp. 11-18 (2019).

40. Parida, A. and Kumar, U. "Maintenance productivity and performance measurement", In Handbook of Maintenance Management and Engineering, Springer London, pp. 17-41 (2019).

41. Ou, H., et al. "The influence of a certain type of radar operator's operating ability on the operational effectiveness of equipment", In Lecture Notes in Electrical Engineering, 576, pp. 599-606 (2020).

42. Hendalianpour, A., Fakhrabadi, M., Zhang, X., et al. "Hybrid model of IVFRN-BWM and robust goal programming in agile and flexible supply chain, a case study: Automobile industry", IEEE Access, 7, pp. 71481-71492 (2019).

43. Fekri, M.S. and Avakh, S.D. "Fuzzy overall equipment effectiveness and line performance measurement using artificial neural network", J. Qual. Maint. Eng., 25(2), pp. 340-354 (2019).

44. Idris, M.R. and Nayan, A.M. "A study on effective production model for higher productivity in manufacturing plant", J. Artif. Intell., 9(4), pp. 82-92 (2016).

45. Nomikos, N.K. and Doctor, K. "Economic significance of market timing rules in the Forward Freight Agreement markets", Transp. Res. Part E Logist. Transp. Rev., 52, pp. 77-93 (2013).

46. Coyle, G. and Exelby, D. "The validation of commercial system dynamics models", Syst. Dyn. Rev., 16(1), pp. 27-41 (2000).

\section{Biographies}

Hossein Kaveh Pishghadam is a PhD Candidate at the School of Industrial Engineering, College of Engineering, Islamic Azad University - North Tehran Branch, Tehran, Iran. His current research interests include digitalization of supply chain, logistics, and transportation. He is currently the Managing Director and Vice-Chairman of Petro Sanat Jonoob Company.

Hamid Esmaeeli is an Assistant Professor at the Department of Industrial Engineering, College of Engineering, Islamic Azad University - North Tehran Branch, Tehran, Iran. His current research interests include the improved business processes, applied statistics, and quality. He is currently a faculty member at the Department of Industrial Engineering. 